Technical Report 1350

\title{
Development of a Mass Casualty Triage Performance Assessment Tool
}

\author{
Christina K. Curnow \\ Jonathan J. Bryson \\ Rachel D. Barney \\ Heidi Keller-Glaze \\ ICF International
}

Christopher L. Vowels

U.S. Army Research Institute

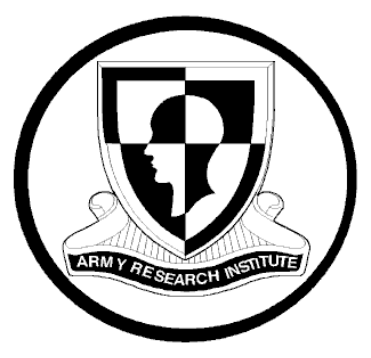

February 2015

United States Army Research Institute for the Behavioral and Social Sciences

Approved for public release; distribution is unlimited. 


\title{
U.S. Army Research Institute for the Behavioral and Social Sciences
}

\author{
Department of the Army \\ Deputy Chief of Staff, G1
}

\section{Authorized and approved:}

\section{MICHELLE SAMS, Ph.D. Director}

Research accomplished under contract

for the Department of the Army by

ICF International

Technical review by

Greg Ruark, U.S. Army Research Institute

Jeremy Oehlert, U.S. Army Research Institute

\section{NOTICES}

DISTRIBUTION: This Technical Report has been submitted to the Defense Information Technical Center (DTIC). Address correspondence concerning ARI reports to: U.S. Army Research Institute for the Behavioral and Social Sciences, Attn: DAPE-ARI-ZXM, $60006^{\text {th }}$ Street Building 1464 / Mail Stop: 5610), Fort Belvoir, VA 22060-5610.

FINAL DISPOSITION: Destroy his Technical Report when it is no longer needed. Do not return it to the U.S. Army Research Institute for the Behavioral and Social Sciences.

NOTE: The findings in this Technical Report are not to be construed as an official Department of the Army position, unless so designated by other authorized documents. 


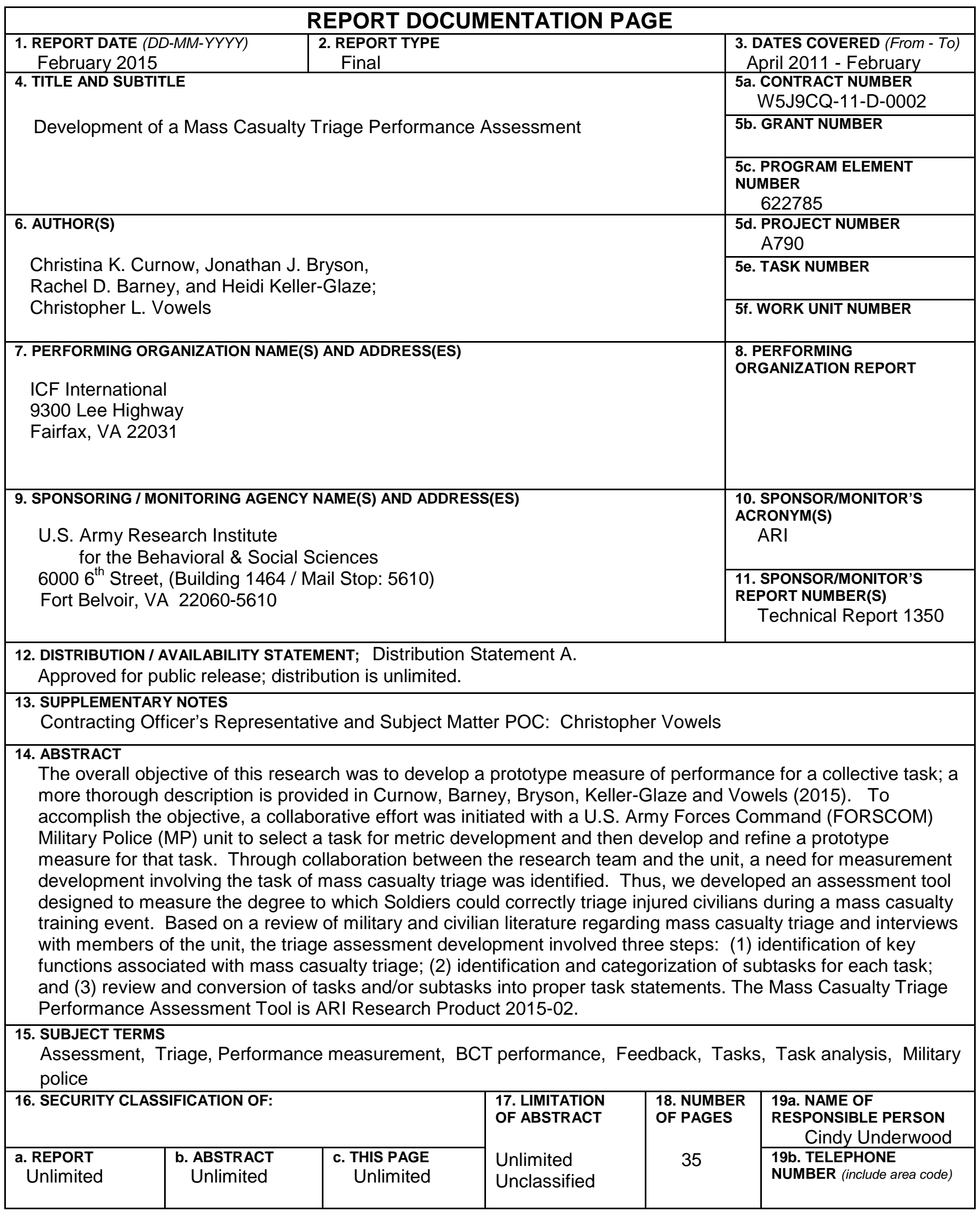




\title{
Technical Report 1350
}

\section{Development of a Mass Casualty Triage Performance Assessment Tool}

\author{
Christina K. Curnow \\ Jonathan J. Bryson \\ Rachel D. Barney \\ Heidi Keller-Glaze \\ ICF International
}

Christopher L. Vowels

U.S. Army Research Institute

Fort Hood Research Unit

Brian T. Crabb, Chief

United States Army Research Institute

for the Behavioral and Social Sciences

February 2015

Approved for public release; distribution is unlimited. 
We would like to thank the unit that identified the need for a mass casualty triage performance assessment tool and then continued to provide input throughout the development and refinement of the assessment tool. 


\section{DEVELOPMENT OF A MASS CASUALTY TRIAGE PERFORMANCE ASSESSMENT TOOL}

\section{EXECUTIVE SUMMARY}

Research Requirement:

The objectives of this research were to develop a prototype measure of a collective task through collaboration with one U.S. Army Forces Command (FORSCOM) Military Police (MP) unit to select a task for metric development and then development and refinement of a prototype measure for that task. However, due to a change in the MP unit's mission, the research was refocused to develop good individual measures in this phase of the research.

Procedure:

A literature review and interviews with members of the selected FORSCOM unit were conducted to identify the tasks associated with performing triage following a mass casualty training event. Task and subtask statements were written. The resulting task list consisted of seven functions, 19 tasks and 39 subtasks. A prototype assessment tool was developed based on those task statements. As a final step in assessment development, Subject Matter Experts (SME) reviewed the assessment and provided feedback for further refinement.

Findings:

The assessment tool comprises six cases. Each case includes a scenario describing the victim's physical state; a list of tasks that must be carried out in order to treat the victim and correctly determine the victim's triage level; and a rating scale. The assessment tool measures declarative knowledge, which involves understanding and remembering facts, such as what each triage color means. It also measures procedural knowledge, which requires a demonstration of skill, such as correctly performing a capillary refill test on the victim's fingernail bed. The tool measures coordination and agility, such as when the student performs the six-step head-tilt/chinlift procedure in the correct sequence in order to position the airway. The measure also tests decision-making ability by presenting examinees with multiple clues that require the examinee to choose the best course of action based on the information presented. They must also decide the correct triage category and tag the victim accordingly. Finally, the assessment measures the speed at which examinees complete the evaluation and tags of the victim.

Utilization and Dissemination of Findings:

A primary result of this research is a triage assessment tool that can be used in contemporary training environments. The procedure and findings also serve as a foundation to conduct further research involving the development of measurement tools for hard-to-measure individual and collective tasks. A more thorough description of the prototype assessment that resulted from this research is given in Curnow, Barney, Bryson, Keller-Glaze, and Vowels, 2015. 


\section{DEVELOPMENT OF A MASS CASUALTY TRIAGE PERFORMANCE ASSESSMENT TOOL}

CONTENTS

Page

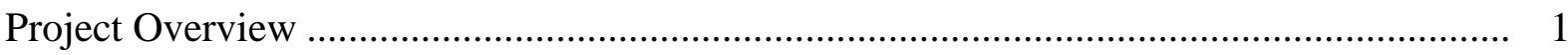

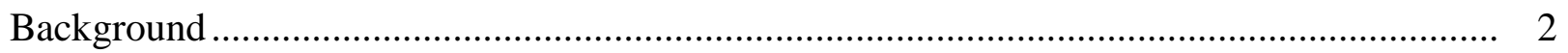

Defense CBRNE Response Force..................................................................................... 2

Validation Exercise ...................................................................................................... 3

Mass Casualty Triage...................................................................................................... 3

Identification of Specific Need .................................................................................. 3

Mass Casualty Triage Defined.......................................................................................... 3

Related Training - Soldier Basic Training ......................................................................... 4

Medical Treatment ......................................................................................................... 4

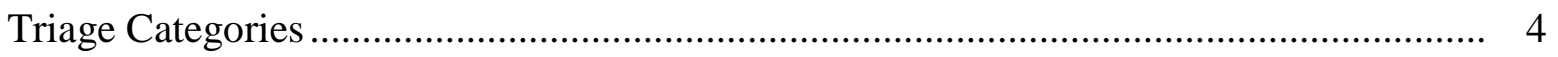

Performing Triage .......................................................................................................... 5

Management of Mass Casualty Events ............................................................................ 6

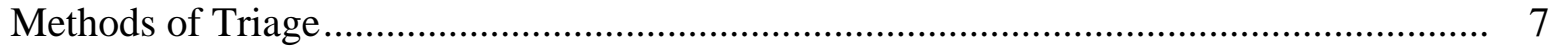

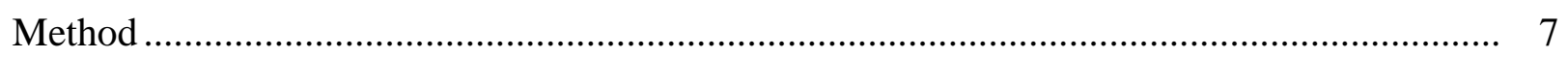

Literature Review..................................................................................................... 7

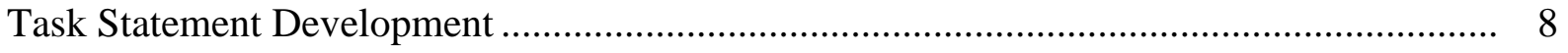

Development of Assessment Tool ................................................................................ 9

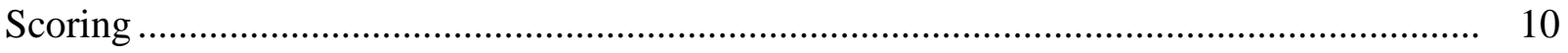

Tool Refinement ....................................................................................................... 10

Assessment Tool Feedback................................................................................... 11

Procedure .......................................................................................................... 11

Summary of Feedback Received ....................................................................................... 11

Limitations, Future Testing/Validation......................................................................... 12

Communication Issues ............................................................................................... 12

Funding Constraints ........................................................................................................ 12

Unexpected Unit Mission Change .................................................................................... 12

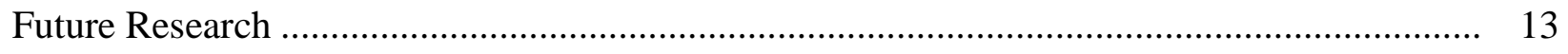

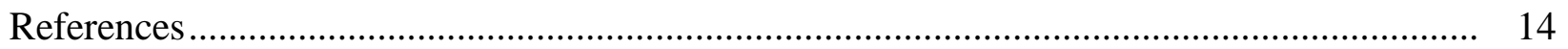




\section{Appendices}

Appendix A. Triage Category …………………………................................................. A-1

Appendix B. Mass Casualty Triage Task Statements .............................................................. B-1

Appendix C. Literature Review Search Terms ...................................................................... C-1

Appendix D. Case 1 from the Mass Casualty Triage Assessment ............................................. D-1

Appendix E. Scoring Rubric ........................................................................................ E-1

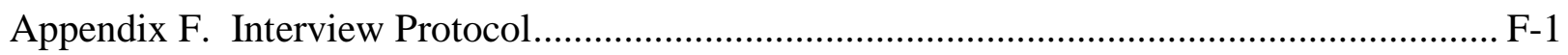




\section{Development of a Mass Casualty Triage Performance Assessment Tool}

In August of 2006, the U.S. Army Research Institute for the Behavioral and Social Sciences (ARI) brought together key stakeholders in Army training and education along with experts from academia, industry, and other military services to "identify learning science findings and technologies to help the Army train Soldiers and grow leaders for today and tomorrow" (Quinkert, Morrison, Fletcher, Moses, \& Roberts, 2007, p. i). One of the key recommendations coming out of this working meeting was a need to develop performance measurement methods and feedback tools that can be used to assess Brigade Combat Team (BCT) performance. The lack of systematic team performance measurement systems within operational settings leaves those in charge having to rely on informal data to determine why teams are effective or ineffective. That is, individuals responsible for creating and maintaining effective teams are asked to assess team performance within complex and dynamic environments, but they are not properly equipped to do so. Quality team performance measurement tools are the only method by which teams can be systematically evaluated to catch problems early before they filter into other areas or before incorrect actions and/or attitudes become ingrained within team member cognition.

\section{Project Overview}

To address this need, the U.S. ARI Ft. Hood Research Unit (ARI-FHRU) set out to investigate difficult-to-assess collective tasks and research methods and best practices relevant to measuring team-based, multi-echelon performance. Research was conducted to achieve the following technical objectives: (1) identify hard to measure collective tasks, (2) determine needed measurement tools, (3) obtain a better understanding of collective performance measurement issues, and to (4) break down selected collective tasks into individual behaviors (Bryson et al., 2014). From this initial research, the following hard to measure collective tasks were identified for further analysis. These included,

- conduct a Key Leader Engagement;

- establish a Host Nation Police Force; and,

- partner with Host Nation Forces.

The follow-on research project described in this report was initiated by ARI-FHRU to develop a prototype measure of performance for one of the three collective tasks identified in the earlier research (see above). The specific objectives of this follow-on research were to collaborate with one U.S. Army Forces Command (FORSCOM) unit to select a task for metric development and then develop and refine a prototype measure for the task. Shortly after starting this follow-on research, the FORSCOM unit supporting the project changed missions from counterinsurgency (COIN) to civil support. Under this new focus, they became part of what is known as the Defense Chemical, Biological, Radiological, and Nuclear (CBRN) Response Force (DCRF) and inherited a new set of mission essential tasks. Given this new set of tasks, the unit no longer placed as much emphasis on the three collective tasks from the earlier research.

Given this new emphasis, we worked with the unit to identify a different task for measurement development. This was done over several months as the unit prepared for and 
attended its first validation exercise. Upon their return, they identified the task of mass casualty triage as an area where assistance was needed. As will be described later in this report, the eventual focus of the assessment tool was not developed to assess multiple echelons. As a result of change to the DCRF mission, the unit expressed an urgent and specific need for measurement to support that mission. As a result, an assessment tool was designed to measure the degree to which Soldiers could correctly triage injured civilians during a mass casualty event.

The purpose of this report is to describe the results of this follow-on research; it is organized into three main sections. The first section provides background information on the project. The second section describes the methodology used in developing and refining the mass casualty triage assessment. The final section provides the project limitations and directions for future testing and validation the tool.

\section{Background}

\section{Defense CBRNE Response Force}

In October of 2009, the United States Northern Command (USNORTHCOM) established two Chemical, Biological, Radiological, Nuclear, and High-yield Explosives (CBRNE) Consequence Management Response Forces (CCMRF) to augment federal consequence management efforts during large scale catastrophic events within the United States (e.g., 9/11, Hurricane Katrina) (Department of the Army, 2011). The first of these, CCMRF1, consisted of primarily active duty forces from the Army, Navy, Air Force, and Marines. The second, CCMRF2, pulled personnel from the Army Reserve and National Guard. Both teams included a headquarters element with three functional task forces (i.e., operations, medical, and aviation) and roughly 4,700 personnel each. A 2011 Army Posture Statement noted the objective of the CCMRFs was to "save lives, mitigate suffering, and enable initial recovery operations" (Department of the Army, 2011).

In October of 2011, following the 2010 Quadrennial Defense Review, USNORTHCOM replaced the CCMRFs with a leaner more integrated capability called the DCRF (Department of the Army, 2010; Kelley, 2012). Under this new structure, the incident response times have been decreased and additional life-saving and life-sustaining assets have been added such as helicopters, emergency medical capabilities, CBRN reconnaissance and decontamination, and search and rescue capabilities (Department of the Army. 2011). The DCRF is divided into two force packages. The first consists of 2,100 personnel ready to deploy within 24 hours of notification. The second consists of 3,100 personnel ready to deploy within 48 hours of notification. A 2011 Army Posture Statement state each force package has a Command and Control CBRN Consequence Response Element (C2CRE) consisting of 1,500 personnel (Department of the Army, 2011). The mission of DCRF remains the same, "to save lives, mitigate human suffering, and facilitate recovery operations in support of civil authorities following a chemical, biological, radiological, or nuclear disaster” (Cohen, 2011, p.1). 


\section{Validation Exercise}

To ensure DCRF units are prepared to deploy and support civilian authorities during natural and man-made disasters, they participate in several USNORTHCOM training exercises (DeHart, 2012). Each training exercise covers a different catastrophic event that could potentially occur within the United States (e.g., hurricanes, homeland invasion, terrorist attack, etc.). Vibrant Response is the largest of these national training exercises (Bielling, 2011). During its last iteration in 2012, it involved approximately 9,000 participants who were tasked with responding to a simulated 10-kiloton nuclear detonation in a major metropolitan area (Burke, 2012). Participants included members from all four branches of the military (both active and reserve components) as well as civilian responders at the local, state, and federal levels (e.g., police departments, hospitals, fire and rescue, FEMA, etc.). The exercise was held across southern Indiana and northern Kentucky (approximately 5,000 square miles) and involved Camp Atterbury’s Muscatatuck Urban Training Complex (MUTC) and 10 other training sites and airfields across the region (U.S. Army North Public Affairs, 2012).

\section{Mass Casualty Triage}

Identification of Specific Need. Being that the DCRF mission is broad and multifaceted, the research team worked with Army SMEs to further identify the specific needs, conditions, and constraints for the assessment tool. We worked closely with the Commander of a Military Police (MP) Company upon his return from the Camp Atterbury Joint Maneuver Training Center (CAJMTC). His Company received an exercise directive, as part of the Vibrant Response exercise, to perform training based on a realistic mass casualty scenario. The Company was required to set up and operate a disaster relief center which included establishing procedures to triage, treat, transfer, and provide humanitarian assistance to 1,000 dislocated civilians per day. The research team was briefed on the mission and provided with After Action Reviews (AAR). The Commander expressed that the most challenging aspects of the exercise included medical triage and evaluating civilians based on the degree of medical attention needed while managing an overflow of injured civilians waiting to be seen. According to briefings and the AAR, the Company did not have the subject matter expertise to properly prepare for the specific tasks related to the mission nor were they able to find appropriate guidance documents to help train them. The Company Commander specifically asked for an assessment tool that would allow him to evaluate whether his Soldiers were triaging correctly based on injuries observed in the casualties. Based on a thorough review of the current civilian and military literature, a lack of assessments designed to measure the effectiveness of triage processes for mass casualty situations was identified. As a result, the research focus was to develop such a tool.

Mass Casualty Triage Defined. Triage is a method that allows patients to be quickly evaluated and medically sorted based on the urgency of the treatment needed, type and seriousness of injury, and likelihood of survival (Community Emergency Response Team, 2011). Typically, triage is performed when the number of injured individuals is high and available medical personnel are limited, as seen in unexpected mass casualty disasters. The goal of triage is to prioritize attention and rapidly identify those who need immediate care, and those who can wait for medical assistance. The strategy is designed to provide the greatest good for the greatest number of victims. Triage also allows for an efficient use of personnel, equipment, and facilities 
while promoting organization and order in situations that are often chaotic. The triage process also uses color-coded tagging system described in detail later in this document (Community Emergency Response Team, 2011).

Related Training - Soldier Basic Training. Many tasks required to perform medical triage are not new to Soldiers. Fundamental medical casualty training is delivered during basic training. Soldiers are taught Tactical Combat Casualty Care (TCCC), which consists of three parts: care under hostile fire; tactical field care; and combat casualty evacuation care (Department of the Army, 2009). Directives are different than those for civilian mass casualty situations since the TCCC conditions are for tactical areas of operations and assume the unit is under fire. Unlike mass casualty situations, TCCC assumes only a small number of casualties requiring care at one time. The training includes evaluating a casualty and performing first aid to clear throat obstructions, preventing or controlling shock, restoring breathing and/or pulse, controlling bleeding, and treating severed extremities and burns.

Medical Treatment. Unlike survival training, medical triage instructs Soldiers not to treat casualties, but instead to sort them based on seriousness and likelihood of survival. Lifesaving strategies such as cardiopulmonary resuscitation (CPR) and first aid are not indicated during initial triage because of the time required and the large number of casualties to evaluate (Bennett, 2008). However, some simple life sustaining procedures are conducted during triage, as described later in this report. Triage assumes that once sorted, medical personnel will then provide treatment and care according to the triage category assigned. Soldiers performing triage are acting as first responders and are considered a bridge to professional medical personnel who are in limited supply and may take some time to arrive on scene or move between casualties. Thus, medical experience is not required for conducting triage.

Triage Categories. When conducting triage, each casualty is categorized according to a color-coded system: Red denotes immediate attention, yellow denotes delayed, green denotes minor, and black suggests a dead or a near death victim. Table 1 below summarizes each triage category and corresponding color. Appendix A describes each triage category in greater detail and presents several examples of each area. 
Table 1

\section{Triage Categories and Corresponding Color}

\begin{tabular}{|c|c|c|}
\hline $\begin{array}{l}\text { Triage } \\
\text { Category }\end{array}$ & Color & Description \\
\hline Immediate & Red & $\begin{array}{l}\text { The victim has life-threatening injuries (airway, bleeding, or shock) } \\
\text { that demand immediate attention to save his or her life; rapid, } \\
\text { lifesaving treatment is urgent. These victims are marked with a red } \\
\text { tag. }\end{array}$ \\
\hline Delayed & Yellow & $\begin{array}{l}\text { Injuries do not jeopardize the victim's life. The victim may require } \\
\text { professional care, but treatment can be delayed. These victims are } \\
\text { marked with a yellow tag. }\end{array}$ \\
\hline Minor & Green & $\begin{array}{l}\text { Walking wounded and generally ambulatory. These victims are } \\
\text { marked with a green tag. }\end{array}$ \\
\hline $\begin{array}{l}\text { Dead or } \\
\text { Expectant }\end{array}$ & Black & $\begin{array}{l}\text { No respiration after two attempts to open the airway. Because CPR is } \\
\text { one-on-one care and is labor intensive, CPR is not performed when } \\
\text { there are many more victims than rescuers. These victims are marked } \\
\text { with a black tag or labeled "DEAD." }\end{array}$ \\
\hline
\end{tabular}

Performing Triage. The triage process typically begins with voice triage, whereby the responder calls out to the casualties and asks that if any can walk, they should move to the sound of the voice and remain in a designated area. These patients are often referred to as the 'walking wounded' and are labeled "Green." They are either tagged with paper tags or with green triage tape (described in the next section). Ambulatory patients are sometimes asked to assist rescuers, when appropriate. After the walking wounded are tagged, the rescuers begin evaluating the nonambulatory patients for airway (breathing/respiration), bleeding (circulation/profusion), and mental status (shock). In triage, airway obstruction, bleeding, and shock are the most significant concerns because without treatment they will lead to death. Note that this type of lifethreatening shock is unrelated to the more commonly understood state known as emotional shock. Medically, shock is a condition where insufficient oxygen is delivered to the cells ultimately leading to cellular death. If untreated, this can progress toward organ failure, and eventually death of the patient (Guyton \& Hall, 2006). The first priority of medical operations is to attend to those concerns by:

- opening the airway;

- controlling excessive bleeding; and

- treating for shock.

Soldiers evaluate each patient and tag them "Red” for immediate, "Yellow" for delayed and "Black" for dead or expectant. Figure 1 below depicts a common algorithm used in Mass Casualty (MASCAL) triage. It provides a decision tree with steps that responders should follow in sequential order. 


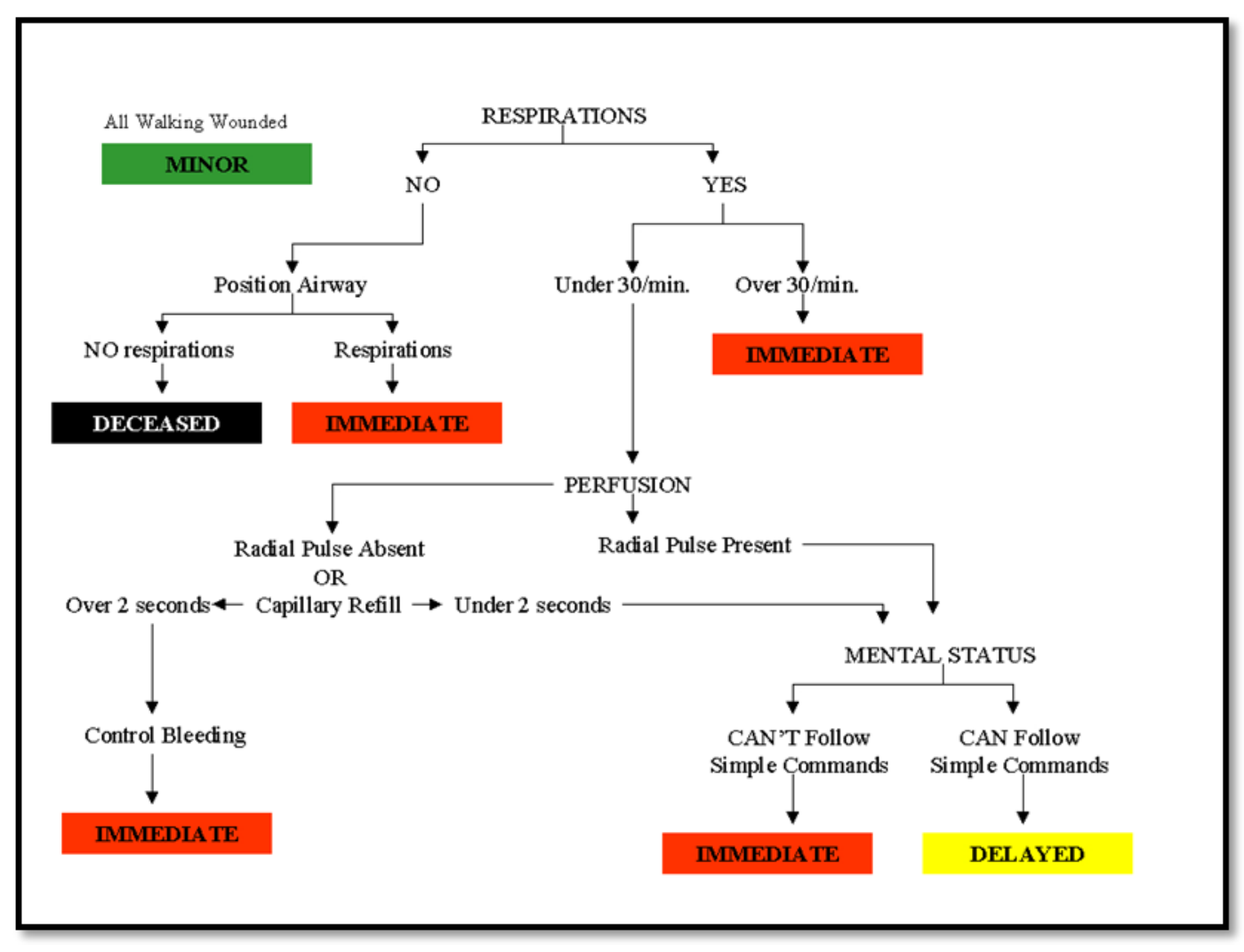

Figure 1. Simple Triage and Rapid Treatment Algorithm.

The following is a simplified translation of the algorithm. Tag all walking wounded as green, for minor injuries. Next, check for respirations. If the victim is not breathing, one should position the airway, if after positioning the airway, the victim is still not breathing, tag him/her black. If after repositioning the airway, spontaneous respirations return, tag him/her red. If respirations were initially present when the victim was encountered, then the responder should measure the number of breaths per minute. If they are over 30 breaths per minute, then they are too rapid and the victim should be tagged red. If they are under 30 breaths per minute, then the responder should check for perfusion (the delivery of blood to an area of the body). If a radial pulse is absent, the responder should perform a capillary refill test. If it takes over 2 seconds for the refill, then control the bleeding and tag red. If the capillary refill takes less than 2 seconds, then check for mental status. If a radial pulse was present initially, then the responder would check for mental status. If the victim cannot follow simple commands, then he/she should be tagged red. If the victim can follow simple commands, then tag him/her yellow. See Appendix B: Mass Casualty Triage Task Statements, for details on how to perform each of the tasks and subtasks described above.

Management of Mass Casualty Events. The military is often tasked with partnering with civilian medical operations as needed during the management of events involving mass casualties. The Department of Defense may coordinate with the Department of Health and Human Services, Federal Emergency Management Agency (FEMA), Emergency Medical Services (EMS), and multijurisdictional public health responders in joint operations. Whether 
mass casualty triage is initiated by the military or civilian responders, general planning considerations are similar and rehearsing and practicing are essential for effective management. FM 4-02.6, The Medical Company, states the following tasks should be included in planning and rehearsing for mass casualty events (Department of the Army, 2002):

- $\quad$ establishing and securing the affected area and creating triage, treatment, and holding areas, including setting up an improvised morgue away from the view of other patients;

- establishing communications between areas, teams, and to higher headquarters, if possible;

- establishing traffic patterns to provide for the smooth flow of patients, and creating routes to different areas; and,

- have nonmedical personnel practice proper techniques for transporting patients, including the loading, carrying, and unloading of litters.

Methods of Triage. There are over a dozen mass casualty triage techniques in use today (Cone, Serrra, \& Kurland, 2012). In the United States (U.S.), two of the most commonly accepted methods are the Simple Triage and Rapid Treatment (START) and the Sort, Assess, Lifesaving Interventions, Treat and Transport (SALT) approaches. The START approach was developed jointly by Newport Beach, California Fire Department and Hoag Hospital and was first implemented in 1985 by the City of Los Angeles Fire Department (LAFD). Since then, the popularity of START has increased. Navin, Sacco, and McGill (2009) suggested it was currently the most widely used approach and Kahn, Schultz, Miller, and Anderson (2009) refer to it as the “defacto" method being used in the U.S.

The SALT approach was developed in 2008 by a working group of experts commissioned by the United States Center for Disease Control and Prevention (CDC) (Lerner et al., 2008). Their purpose was to create a mass casualty triage system that could serve as a national standard for triage in the U.S. To do this, they analyzed existing mass casualty triage systems currently employed and used best practices from these to create a hybrid system. For purposes of this research, the START method was selected over SALT, as START tended to be a more familiar approach and was seen as the method of choice for many local, state, and federal agencies. For instance, the Community Emergency Response Team (CERT) training provided by FEMA uses the START method of triage (Community Emergency Response Team, 2011).

\section{Method}

\section{Literature Review}

A thorough review of relevant documents was conducted to gain a better understanding of the current state of medical triage, how it is performed, its efficacy, and to identify any triage assessment tools were existent in the field. A range of electronic data sources were identified using a list of related search terms. Data sources consulted include: Army Knowledge On-line (AKO), Army Publishing Directorate (APD), Center for Army Lessons Learned (CALL), EBSCOhost (e.g., PsycINFO, ERIC, and Military \& Government Collection), U.S. Army Research Institute for the Behavioral and Social Sciences, Defense Technical Information Center 
(DTIC), Combined Arms Research Library (CARL) digital library, and Google web search. Appendix $C$ displays the search terms. Various parings and combinations of the search terms were used.

Documents explored both military and civilian documents, including Army field manuals, disaster preparedness manuals, academic journal articles, EMS guides, fire and rescue training documents, and Army Doctrine Publications. Triage guidance documents and manuals were also examined from several Federal government agencies, such as FEMA, CDC, and Agency for Healthcare Research and Quality (AHRQ).

\section{Task Statement Development}

From the results of the literature review, a task list for conducting mass casualty triage was developed. This involved a three step process. First, the key functions associated with mass casualty triage were identified. Each of these functions consisted of multiple tasks. For example, the function of "check airway and breathing rate" involved the following tasks:

1) Check consciousness of the casualty;

2) Position casualty onto back;

3) Open airway of casualty;

4) Check the casualty for breathing;

5) Check breathing rate of casualty; and,

6) Maintain the airway of the casualty.

Each duty along with its corresponding task(s) was entered into an Excel database for further analysis (see Appendix B). Second, subtasks (or steps) for each task (if any) were identified and entered into the database under their respective task. For example, the task of "check the casualty for bleeding" included four subtasks:

1) look for blood-soaked clothing;

2) look for wounds;

3) place hand behind the victim's neck and pass them upward toward the top of the head checking for blood; and,

4) place your hands behind the victim's shoulders and pass them downward behind the back, the thighs, and the legs.

Third, tasks and/or subtasks were reviewed and converted into proper task statements. This involved making sure each task started with a verb followed by a direct object (Brannick, Levine, \& Morgeson, 2007). In addition, qualifiers were added where possible to clarify how, when, or why the task was being done. For example, "sweep the casualties' mouth in order to remove obstructions." The resulting task list consists of seven functions, 19 tasks and 39 subtasks. 


\section{Development of Assessment Tool}

An assessment instrument was developed to measure Soldier readiness to triage injured civilians during a mock mass casualty exercise. The tool is categorized as a work sample, which is a test that requires examinees to perform tasks under conditions similar to those in which the task is performed on the job (Felker, Curtin, \& Rose, 2007). The tool was developed with the assumption that Soldiers would learn basic triage procedures including the color-coded tagging system used in the process prior to participating in a training exercise. The assessment is based in part on the START approach, which is one of the more widely used triage methods for dealing with mass casualties in a disaster (Kahn et. al., 2009). The assessment is observational and designed to be used either in the classroom or in the field. The purpose of the tool is to allow students to demonstrate triage activities, including evaluating a victim physically and making key decisions. The assessment comprises six cases and each includes a scenario describing the victim's physical state, a list of tasks that must be carried out in order to treat the victim and correctly determine the victim's triage level, and a rating scale. Recall that triage only includes basic treatment that can be executed quickly and without medical experience. Examples of acceptable triage treatment activities include repositioning the airway if respirations are not present, controlling bleeding, and elevating the feet to treat for shock.

The tool allows for measurement of declarative knowledge which involves understanding and remembering facts, such as what each triage color corresponds to (e.g., Red=Immediate). It also measures procedural knowledge, which requires a demonstration of skill, such as correctly performing a capillary refill test on the victim's fingernail bed. The tool also allows for measurement of coordination and agility, or the "ability to perform motor activities in a proficient sequential pattern by using neurosensory cues such as change of direction" (Gebhardt \& Baker, 2010, p. 170) that could occur when the student performs the six-step head-tilt/chin-lift procedure in the correct sequence in order to position the airway. Further, the tool provides a test of decision-making ability by presenting examinees with multiple clues that require the examinee to choose the best course of action based on the information presented (e.g., when presented with a capillary refill that takes more than five seconds, they should choose to treat the victim for shock instead of proceeding to tests of mental status). The student/trainee must also decide the correct triage category and tag the victim accordingly. Finally, the tool permits for measurement of the speed at which examinees complete the evaluation and tagging of the victim.

The tool was designed for one assessor to observe the triage tasks performed and provide ratings of Soldiers performing triage individually or in teams of two. The tool includes instructions for the assessor to make proficiency ratings and provide critical feedback about the victim's state to the Soldier being evaluated. In addition, assessors must measure the time it takes to triage each victim and should expect that each is completed in one minute or less. If the triage scenario is being executed by a team of two or three Soldiers, then coordination, communication and monitoring skills would be required for successful performance. A portion of the final version of the assessment tool can be found in Appendix D. 


\section{Scoring}

Due to the multi-dimensional nature of the mass casualty triage assessment, the development and use of an analytic rubric was deemed most appropriate for scoring purposes (Mertler, 2001). Under this technique, separate scores are provided for each criterion (or factor) being evaluated. These scores are then combined to create an overall performance score. Analytic rubrics have several key advantages over other types of scoring instruments (e.g., checklists; Mertler, 2001). First, it gives the evaluator more detailed and specific feedback on the person being assessed. Second, it provides the person being assessed with a greater understanding of where his or her own strengths and weaknesses lie on the task. Finally, it makes scoring of the assessment more objective and consistent across the different individuals being assessed (Mandernach, 2003; Mertler, 2001).

A three step process was used in the development of the analytic rubric for the mass casualty triage assessment. First, the level of performance was identified for each criterion. Mueller (2012) suggested using a small number of levels (i.e., 2 to 3) to avoid potential consistency issues with scoring. The goal was to have an adequate number of performance levels in order to make meaningful distinctions between Soldiers. The team decided on three levels of performance for each criterion. These were as follows:

- $1=$ Novice;

- 2=Intermediate; and,

- $3=$ Advanced.

From there, each criterion was reviewed for importance in relations to the other criteria. Mueller (2012) suggested that weighting of scores is needed when one criterion in the assessment is seen as more important than another. It was determined that all three criteria on the mass casualty triage assessment were of equal importance so no weighting was required.

Finally, statements of expected performance or "descriptors" were added to each level of performance under each criterion (Mueller, 2012). This was done to clarify 'what right looks like' at each level of performance. For example, in order for a person to achieve a 3 or Advanced on the "task" criterion, he or she needs to complete all steps correctly and without difficulty for all triage tasks. The final version of the analytic scoring rubric is provided in Appendix E.

\section{Tool Refinement}

The purpose of this task was to collect feedback from potential users of the triage tool, clarify uncertainties, confirm that other similar tools were not already in use, and improve and refine the tool. Interviews with SMEs were conducted prior to development of the tool, during development, and again after the tool was completed. The SME review also ensured that the following points were addressed.

1. The tool measures what it is intended to measure and is relevant (face validity).

2. The tool addresses an important need and is perceived by SMEs as useful. 
3. The tool aligns with current military mass casualty training and exercises.

4. The tool uses terms and jargon appropriate for civilian triage performed by the military.

5. The scoring approach is appropriate and practical for ultimate users of the tool.

\section{Assessment Tool Feedback}

This task involved data collection with three samples of participants. The first sample was comprised of a company commander and an executive officer (XO). The second sample included a senior medic and a platoon leader. The third sample consisted of a company commander, XO, senior medic, and a platoon leader.

Procedure. An interview protocol was developed to collect feedback from participants (Appendix F). The protocol was ultimately used as a focus group guide and as an open-ended questionnaire whereby participants completed the questions and returned them via email. The entire protocol consisted of seven sections:

1. introduction describing the project purpose, confidentiality, and privacy act statement;

2. several interview questions assessing current triage methods, practicality of the assessment tool, and challenges with using the tool, the rating scale, or the assessment instructions;

3. background information about the assessment tool, its development, and intended use;

4. a summary of the triage categories with descriptions of each color;

5. the assessment tool, which included six case examples, triage items, and rating scales.

6. scoring rubric; and,

7. detailed examples of the triage categories in the appendix of the protocol.

\section{Summary of Feedback Received}

The first sample of participants provided feedback that focused on how the assessment would provide features over and above their current triage assessment methods. In addition, they described preferences and qualities they wanted to see incorporated into the tool. For example, they mentioned that during training exercises they were currently triaging civilians based on the degree to which they were ambulatory or not and did not have methods of determining the severity of injuries. They also suggested that the tool be developed to be used both in the field and in the classroom.

The second sample informed us that they would be developing a triage training program based on FEMA standards and that the training would align with the assessment tool we presented. They described how their current experience with mass casualty triage is slanted towards battlefield situations and less on civilian populations. They commented on how they needed to shift priorities since hostile fire was no longer a consideration in civilian mass casualties. They provided examples of how "life, limb, and eyesight" related wounds were categorized as immediate or red in the battlefield, whereas "airway, bleeding, and shock" constitute the immediate category in civilian triage. They also described other examples, such as how their Standard Operating Procedure (SOP) requires that they conduct triage in 3 minutes instead of the more commonly-accepted benchmark of one minute. 
The third sample described what they valued about the tool and what challenges they predicted. First, they appreciated that the rating scale provided more variability than conventional go/no go checklists. They also asked that we add additional space for assessors to make notes on Soldier performance to aid with coaching and feedback. They predicted that the main challenge with the tool was going to be the inevitable subjectivity of ratings. The Soldiers also noted, although the measure would be ideal for individual tasks, it did not provide sufficient opportunities for platoon leaders or company commanders to evaluate their targets. Typically, evaluation occurs two levels down. In this case, a company commander would evaluate platoon sergeants and platoon leaders would evaluate squad leaders. In addition, they suggested that future assessment development focus on successively difficult questions as individual skill levels advance. As one moves up the echelons, items would shift to incorporate decision-making, strategic thinking, problem solving, and situational awareness.

\section{Limitations, Future Testing/Validation}

There are many risks associated with conducting research in the real world. During the course of this project, we encountered many. However, the experience provided an interesting look into limitations that can influence the outcome of this kind of research. During the course of this project, we experienced the following challenges.

\section{Communication Issues}

The unit was very responsive during the initial phases of the project. However, over time communication with the unit began to decline as day-to-day activities and other events took priority over assisting with the research. The SMEs became somewhat less responsive to e-mails and phone calls. When the unit did respond, it was primarily through email and often their answers were incomplete or required further clarification that they were unable to provide. For example, some SMEs inadvertently fluctuated between battlefield triage and civilian triage when describing their exercises which caused some confusion.

\section{Funding Constraints}

The unit was scheduled to attend a validation exercise at a combat training center. This was an opportunity to test and validate the mass casualty triage assessment tool. However, due to funding issues, the unit cancelled its participation in the exercise. This prevented us from being able to pilot test the instrument.

\section{Unexpected Unit Mission Change}

As mentioned earlier, we encountered this issue shortly after starting the follow-on project when the unit changed missions from counterinsurgency to civil support. As a result, the tasks originally identified for metric development were no longer relevant, causing us to switch the focus of the assessment tool. Although the mission change expanded our timeline, the development of the new tool emphasized the importance of mass casualty triage especially considering the increasing threats of terrorism and intentional mass casualty on the United States (Barbera \& Macintyre, 2002). 


\section{Future Research}

Results from the current project suggest two potential directions for future research. The first avenue would be to pilot test and validate the mass casualty triage assessment tool. This would be a natural follow-on to the current research and would allow us to maximize the validity, reliability, and utility of the instrument. In addition, research in this area could be expanded beyond the individual task of triage, to more collective levels of triage. For example, researchers could look into the types of communication and coordination (if any) used during mass casualty triage at the squad and platoon levels. Findings could help inform additional items for the assessment.

Second, a measure(s) could be developed to assess performance on one or more of the three collective tasks already identified in the earlier research (i.e., Conduct a Key Leader Engagement, Establish a Host Nation Police Force, and Partner with Host Nation Forces). This line of research would require researchers to find a new unit to collaborate with, one that needed assistance in one of more of these areas, and working with them to develop an assessment measure. The measure could then be pilot tested and validated for use by commanders in assessing their unit's performance on that task. 


\section{References}

Barbera, J. A. \& Macintyre, A. G. (2002). Medical and health incident management (MaHIM) system: Comprehensive functional system description for mass casualty medical and health incident management. Washington, DC: Institute for Crisis, Disaster, and Risk Management, The George Washington University.

Bennett, A. D. (2008). Disaster Preparedness-First Aid Medical Operations Instructor Guide. Kitsap County Department of Emergency Management. Retrieved on August 16, 2012 from http://www.kitsapdem.org/pdfs/biz_schools/Disaster\%201st\%20 Aid_Chap\%202.pdf

Bielling, P. (2011). Army North’s largest exercise to train DoD’s newest response forces. Retrieved on February 18, 2013 from http://www.army.mil/article/60696/

Brannick, M. T., Levine, E. L., \& Morgeson, F. P. (2007). Job and work analysis. Thousand Oaks, CA: Sage Publications.

Bryson, J., Barney, R., Curnow, C., Conrad, T., Leonard, A., Keller-Glaze, H., Tucker, J. S., \& Vowels, C. L. (2014). Task analyses for difficult-to-assess collective tasks. (Research Product 2014-05). Fort Belvoir, VA: U.S. Army Research Institute for the Behavioral and Social Sciences.

Burke, C. (2012). On the ground at vibrant response 13. Small Wars Journal. Retrieved on February 18, 2013 from http://smallwarsjournal.com/blog/on-the-ground-at-vibrantresponse-13.

Cohen, B. (2011). Fort Polk brigade to provide WMD response nationwide. Retrieved on February 18, 2013 from http://www.bioprepwatch.com/news/fort-polk-brigade-toprovide-wmd-response-nationwide/272047/

Community Emergency Response Team (2011). Basic training instructors guide. Federal Emergency Management Agency (FEMA), Department of Homeland Security, Washington, DC.

Cone, D. C., Serrra, J., \& Kurland, L. (2012). Comparison of the SALT and SMART triage systems using a virtual reality simulator with paramedic students. Europe Journal of Emergency Medicine, 18, 314-321.

Curnow, C. K., Barney, R. D., Bryson, J. J., Keller-Glaze, H., \& Vowels, C. L. (2015). Mass casualty triage performance assessment. (Research Product 2015-02). Fort Belvoir, VA: U.S. Army Research Institute for the Behavioral and Social Sciences.

DeHart, C. (2012). TF51 turns training into real-world knowledge during VR13 exercise. Retrieved on February 18, 2013 from www.arnorth.army.mil/TF51-turns-training-intoreal-world-knowledge-duri.aspx. 
Felker, D. B., Curtin, P. J., \& Rose, A. M. (2007). Tests of job performance. In D. L. Whetzel \& G. R. Wheaton (eds.), Applied Measurement: Industrial Psychology in Human Resources Management (pp. 319-38). Mahway, NJ: Erlbaum

Gebhardt, D. L., \& Baker, T. A. (2010). Physical performance. In J. C. Scott \& D. H. Reynolds (eds.), Handbook of Workplace Assessment (pp. 165-196). San Francisco: Jossey-Bass

Guyton, A., \& Hall, J. (2006). Chapter 24: Circulatory Shock and Physiology of its Treatment. In Gruliow, Rebecca. Textbook of Medical Physiology (11th ed., pp. 278-288.). Philadelphia, PA: Elsevier.

Kahn, C. A., Schultz, C. H., Miller, K. T., \& Anderson C. L. (2009). Does START triage work? An outcomes assessment after a disaster. Annuals of Emergency Medicine, 54, 424-430.

Kelley, V. (2012). DoD/national defense public safety today: CBRN protection - From CCMRF to DCRF: Changing letters for better results. Homeland Security Today. U.S. Retrieved on February 18, 2013 from http://www.hstoday.us/channels/fema/singlearticle-page/public-safety-today-cbrn-protection-from-ccmrf-to-dcrf-changing-letters-forbetter-results/8d0a0e4756f7f68e79e8e3f9933ac965.html

Lerner, E. B., Schwartz, R. B., Coule, P. L., Weinstein, E. S., Cone, D. C., Hunt, R. C., Sasser, S. M., Liu, M., Nudell, G., Ian, S., \& Wedmore, et al. (2008). Mass casualty triage: An evaluation of the data and development of a proposed national guideline. Disaster Medicine and Public Health Preparedness, 2 Suppl 1: S25-S34.

Mandernach, B. J. (2003). Authentic assessment. Retrieved on February 18, 2013, from http://www.park.edu/cetl/quicktips/authassess.html

Mertler, C. A. (2001). Designing scoring rubrics for your classroom. Practical Assessment, Research \& Evaluation, 7(25). Retrieved on February 18, 2013 from https://resources.oncourse.iu.edu/access/content/user/mikuleck/Filemanager_Public_Files /EFL_Assessment/Unit_3/Metler_Designing_scoring_rubrics_for_your_classroom.pdf

Mueller, J. (2012). Rubrics. Authentic Assessment Toolbox. Retrieved February 18, 2013, from http://jfmueller.faculty.noctrl.edu/toolbox/rubrics.htm

Navin, D. M., Sacco, W. J., \& McGill, G. (2009). Application of a new resource-constrained triage method to military-age victims. Military Medicine, 174, 1247-1255.

Quinkert, K. A., Morrison, J. E., Fletcher, J. D., Moses, F. L., \& Roberts, E. J. (2007). The Army science of learning workshop. (Research Note No. 2007-02). Arlington, VA: U.S. Army Research Institute for the Behavioral and Social Sciences.

U.S. Army North Public Affairs (2012). Major exercise builds solidarity amongst local, state, federal agencies. Retrieved February 18, 2013 from 
http://www.arnorth.army.mil/News/Major-exercise-builds-solidarity-amongst-local,st.aspx

U.S. Department of the Army. (2002). Field manual 4-02.6, The medical company. Author: Washington, DC.

U.S. Department of the Army. (2009). Solider training publication 21-1-SMCT, Soldier's manual of common tasks warrior skills level 1. Author: Washington, DC.

U.S. Department of the Army. (2010). Field manual 3-28, Civil support operations. Author: Washington, DC.

U.S. Department of the Army. (2011) Army posture statement. Retrieved on February 18, 2013 from https://secureweb2.hqda.pentagon.mil/vdas_armyposturestatement/2011/pages/ Transition.aspx 


\section{Appendix A: Triage Category}

\begin{tabular}{|c|c|c|c|}
\hline Category & Priority & $\begin{array}{l}\text { Description } \\
\end{array}$ & Tag \\
\hline $\begin{array}{l}\text { Red } \\
\text { (Immediate } \\
\text { Critical } \\
\text { Priority 1) }\end{array}$ & Highest & $\begin{array}{l}\text { Patients whose lives are in immediate danger } \\
\text { and who require immediate treatment } \\
\text { Transport as soon as possible }\end{array}$ & $\begin{array}{l}\text { Patient has life-threatening but treatable injuries } \\
\text { requiring rapid attention } \\
\text { Ventilations present only after repositioning the } \\
\text { airway } \\
\text { Respiratory rate over } 30 \text { per minute } \\
\text { Capillary refill greater than } 2 \text { seconds } \\
\text { No radial pulse } \\
\text { Unable to follow simple commands } \\
\text { Examples: } \\
\text { Airway \& breathing difficulties } \\
\text { Uncontrolled or severe bleeding } \\
\text { Decreased level of consciousness } \\
\text { Severe medical problems } \\
\text { Shock } \\
\text { Severe burns } \\
\text { Cardiorespiratory failure } \\
\text { Deep chest wound }\end{array}$ \\
\hline $\begin{array}{l}\text { Yellow } \\
\text { (Delayed } \\
\text { Urgent } \\
\text { Priority 2) }\end{array}$ & Second & $\begin{array}{l}\text { Patients whose lives are not in immediate } \\
\text { danger and who will require urgent, not } \\
\text { immediate, medical care; these patients are } \\
\text { generally non-ambulatory. } \\
\text { Delay temporarily ( } 45 \text { minutes or longer) }\end{array}$ & $\begin{array}{l}\text { Patient has serious injuries but is stable enough to } \\
\text { wait a short while for medical treatment } \\
\text { Able to obey commands } \\
\text { Has peripheral pulse } \\
\text { Not in respiratory distress } \\
\text { Major hemorrhage is controlled } \\
\text { Examples: } \\
\text { Burns without airway problems } \\
\text { Major or multiple bone or joint injuries } \\
\text { Back injuries with or without spinal cord damage } \\
\text { Open thoracic wound } \\
\text { Penetrating abdominal wound } \\
\text { Severe eye injury } \\
\text { Avascular limb } \\
\text { Fractures } \\
\text { Significant burns other than face, neck or perineum }\end{array}$ \\
\hline $\begin{array}{l}\text { Green } \\
\text { (Minimal Minor } \\
\text { Ambulatory } \\
\text { Priority 3) }\end{array}$ & Low & $\begin{array}{l}\text { Patients with minor injuries who will } \\
\text { eventually require treatment } \\
\text { Treatment and transport delayed until last }\end{array}$ & $\begin{array}{l}\text { Patient requires some medical attention but is able } \\
\text { to walk and can wait longer periods of time for } \\
\text { treatment } \\
\text { - } \quad \text { Separate from the general group at the } \\
\text { beginning of the triage operation. ("Walking } \\
\text { wounded") } \\
\text { - } \begin{array}{l}\text { Direct patients away from the scene to a } \\
\text { designated safe area }\end{array} \\
\text { - } \quad \text { Consider using these patients to assist in } \\
\text { treatment of those patients tagged as } \\
\text { immediate } \\
\text { Examples: } \\
\text { - Minor fractures } \\
\text { - Minor soft tissue injuries } \\
\text { - } \quad \text { Contusions lacerations } \\
\text { - Sprains } \\
\text { Superficial burns }\end{array}$ \\
\hline $\begin{array}{l}\text { Black } \\
\text { (Expectant } \\
\text { Expired } \\
\text { Deceased) }\end{array}$ & Lowest & $\begin{array}{l}\text { Description: Patients who are either dead or } \\
\text { who have such extensive injuries that they } \\
\text { cannot be saved with the limited resources } \\
\text { available. }\end{array}$ & $\begin{array}{ll}\text { - } & \text { Obvious death; signs of impending death } \\
\text { - } & \text { Obviously non-survivable injury, such as } \\
\text { major open brain trauma } \\
\text { - } & \text { Full cardiac arrest } \\
\text { - } & \text { No ventilations present even after attempting } \\
& \text { to reposition the airway } \\
\text { - } & \text { Multisystem trauma } \\
\text { - } & \text { Severe burns covering over } 90 \% \text { of body }\end{array}$ \\
\hline
\end{tabular}




\section{Appendix B: Mass Casualty Triage Task Statements}

Objective: The process of sorting casualties into groups based on their need for or likely benefit from immediate medical treatment.

Key:

- Light Blue Shading - Functions

- Gray Shading - Tasks

- No Shading - Subtasks (or Steps) required to complete a given task

\section{TRIAGE}

\section{CONDUCT VOICE TRIAGE}

Call out to the casualties, "our team is here to help."

Call out to the casualties, "if you can walk, come to the sound of my voice."

Instruct casualties who are ambulatory to remain in the designated location.

\section{CHECK AIRWAY AND BREATHING RATE}

Check consciousness of casualty

Shake the casualty gently to see if he or she is conscious.

Ask the casualty in a loud voice, "are you alright."

Position casualty onto his or her back.

1. Raise the near arm of the casualty and straighten it out above their head.

2. Adjust the legs of the casualty so they are together and straight or almost straight.

3. Place one hand on the back of the casualty's head and neck.

4. Grasp the casualty under the arm with the free hand.

5. Pull the casualty in a steady and even manner toward yourself, keeping their head and neck in line with their torso.

6. Roll the casualty as a single unit.

7. Place the casualty's arms at his/her sides.

Open airway of casualty.

1. Kneel at the level of the casualty's shoulders.

2. Place one hand on the casualty's forehead and apply firm backward pressure with the palm to tilt the head back.

3. Place the finger tips of the other hand under the bony part of the casualty's lower jaw and lift, bringing the chin forward.

Check the casualty for breathing.

4. Look into the casualty's mouth and sweep for obstructions (e.g., vomit) using your index finger.

5. Place ear over casualty's mouth and nose to listen and feel for air movement (this includes looking for the chest to rise and fall, listening for air exchange, and feeling for abdominal movement).

Check breathing rate of casualty.

Count the number of chest rises within 30 seconds and multiply by 2 .

Maintain the airway of the casualty.

Slide a soft object under the casualty's shoulders to slightly elevate the shoulders, which will keep the airway open.

CONTROL BLEEDING

Check the casualty for bleeding.

1. Look for blood-soaked clothing. 


\section{TRIAGE}

2. Look for wounds.

3. Place hand behind the casualty's neck and pass them upward toward the top of the head checking for blood.

4. Place your hands behind the casualty's shoulders and pass them downward behind the back, the thighs, and the legs.

Control the casualties bleeding.

5. Put pressure on the nearest pressure point (between the wound and the heart) and elevate the wound above the level of the heart to slow the flow of blood to the wound.

Uncover the wound.

6. Apply a clean dressing over the wound.

7. Apply pressure to the dressing over the wound.

8. Wrap a pressure bandage around the dressing over the wound.

9. Elevate wound above heart (for extremities only).

\section{CHECK CIRCULATION}

Check the circulation of the casualty (blanch test for capillary refill).

1. Press on an area of skin on the casualty until normal skin color is gone.

2. Time how long it takes for normal color to return.

\section{TREAT FOR SHOCK}

Check the casualty for shock.

Check the casualty for symptoms of shock.

Position the casualty on his or her back.

1. Raise the near arm of the casualty and straighten it out above their head.

2. Adjust the legs of the casualty so they are together and straight or almost straight.

3. Place one hand on the back of the casualty's head and neck.

4. Grasp the casualty under the arm with the free hand.

5. Pull in a steady and even manner toward yourself, keeping the head and neck of the casualty in line with the torso.

6. Roll the casualty as a single unit.

7. Place the casualty's arms at his/her sides.

8. Loosen tight or binding clothing on the casualty.

9. Elevate the casualty's feet 6-10 inches above the level of the heart.

10. Maintain the casualty's body temperature by covering the ground and/or the casualty with a blanket.

11. Calm and reassure the casualty.

\section{CHECK MENTAL STATUS}

Ask the casualty to squeeze your hand.

Watch the casualty to see how they respond to the command.

\section{TAG CASUALTY}

Look for the most observable place to tag the casualty.

Tag the casualty with the appropriate triage tag for his or her injury (i.e., Immediate, Delayed, Expectant, Minimal). 


\section{Appendix C: Literature Review Search Terms}

$\begin{array}{llll}\text { Search Terms } & & \\ \text { - Triage } & \bullet \text { Trauma } & \text { Injured casualties } \\ \text { - Triage tag } & \bullet \text { Multiple casualties } & \text { - Injured civilians } \\ \text { - Medical triage } & \text { - Disaster triage } & \text { - Triage CERT SALT } \\ \text { - Triage assessment } & \bullet \text { Catastrophic } & \text { START } \\ \text { - Emergency medical } & & \text { emergency } & \text { Simple Triage and } \\ \text { - Mass casualty } & \bullet \text { Field triage } & \text { Rapid Treatment } \\ \text { - Emergency response } & \bullet \text { Triage tool } & \text { Simulated mass } \\ \text { - Disaster response } & \bullet \text { Military medical } & \text { casualty } \\ \text { - Triage Categories } & \bullet \text { Emergency first aid } & \\ \text { - Triage training } & \bullet \text { Military triage } & \end{array}$




\section{Appendix D: Case 1 from the Mass Casualty Triage Assessment}

Case 1: Wounded civilian is not ambulatory, is lying on his/her side, and has minor burns to the arms, and bruising to the head and neck.

\begin{tabular}{|c|c|c|c|}
\hline \multicolumn{4}{|l|}{ Tasks Required } \\
\hline Task & $\begin{array}{l}\text { Performed } \\
\text { Correctly } \\
\checkmark\end{array}$ & $\begin{array}{l}\text { Performed } \\
\text { Incorrectly or } \\
\text { with Difficulty } \\
\qquad \checkmark\end{array}$ & $\begin{array}{l}\text { Task } \\
\text { Excluded } \\
\qquad \\
\checkmark\end{array}$ \\
\hline \multicolumn{4}{|l|}{$\begin{array}{l}\text { Check for consciousness } \\
\text { - } \quad \text { Shake casualty and speak loudly at arm's distance. }\end{array}$} \\
\hline \multicolumn{4}{|l|}{$\begin{array}{l}\text { Position the casualty } \\
\text { - } \quad \text { Raise the near arm of the casualty and straighten it out above their head. } \\
\text { - } \text { Adjust the legs of the casualty so they are together and straight or almost } \\
\text { straight. } \\
\text { - } \quad \text { Place one hand on the back of the casualty's head and neck. } \\
\text { - } \quad \text { Prasp the casualty under the arm with the free hand. } \\
\text { head and neck in line with their torso. } \\
\text { - } \quad \text { Roll the casualty as a single unit. } \\
\text { Place the casualty's arms at his/her sides. }\end{array}$} \\
\hline \multicolumn{4}{|l|}{$\begin{array}{l}\text { Look, listen and feel for breathing } \\
\text { - } \quad \text { Place ear over casualty's mouth and nose to listen and feel for air movement. } \\
\text { - } \quad \text { Look for the chest to rise and fall. } \\
\text { - } \quad \text { Listen for air exchange. } \\
\end{array}$} \\
\hline \multicolumn{4}{|c|}{\begin{tabular}{l|l|l} 
Check breathing rate & & \\
- $\quad$ Count the number of chest rises within 15 seconds and multiply by 4. & & \\
\end{tabular}} \\
\hline \multicolumn{4}{|c|}{ Assessor Feedback: Breathing rate is 20 breaths per minute } \\
\hline $\begin{array}{l}\text { Check for bleeding } \\
\text { - Look for blood-soaked clothing. } \\
\text { - } \quad \text { Pook for wounds. } \\
\text { Place hand behind the casualty's neck and pass them upward toward the top of } \\
\text { - Place your hands behind the casualty's shoulders and pass them downward } \\
\text { behind the back, the thighs, and the legs. }\end{array}$ & & & \\
\hline \multicolumn{4}{|c|}{ Assessor Feedback: No bleeding discovered } \\
\hline \multirow{2}{*}{\multicolumn{4}{|c|}{$\begin{array}{l}\text { Check circulation using blanch test for capillary refill } \\
\text { - } \quad \text { Press on an area of skin or on finger nail until normal skin color is gone. } \\
\text { - Time how long it takes for normal color to return. }\end{array}$}} \\
\hline & & & \\
\hline $\begin{array}{l}\text { Treat for shock } \\
\text { - } \quad \text { Elevate feet 6-10 inches above heart and maintain body temperature with } \\
\text { blanket, if available. }\end{array}$ & & & \\
\hline
\end{tabular}




\section{Triage Category}
Red
Yellow
Green
Black

\section{Time to Completion}

Minutes

Seconds

\section{Scoring Section}

Fill in each dimension with either a 1 = Novice; 2 = Intermediate; or 3 = Advanced

\begin{tabular}{c|c|} 
Tasks Required & \\
Triage Category + & \\
Time to Completion + & \\
Overall Score & \\
\end{tabular}




\section{Appendix E: Scoring Rubric}

The scoring rubric consists of three dimensions that correspond to the three sections of the mass casualty assessment tool; specifically, tasks required, triage category, and time to completion (see below). For each of these dimensions there are three levels of performance $(1=$ Novice, $2=$ Intermediate, and 3 = Advanced) with descriptions of what is expected at each of these levels.

\begin{tabular}{|c|c|c|c|}
\hline Criteria & $\begin{array}{c}1 \\
\text { Novice }\end{array}$ & $\begin{array}{c}2 \\
\text { Intermediate }\end{array}$ & $\begin{array}{c}3 \\
\text { Advanced }\end{array}$ \\
\hline Task & $\begin{array}{l}\text { Missed (or performed } \\
\text { incorrectly or with } \\
\text { difficulty) one or more } \\
\text { steps on two or more of } \\
\text { the triage tasks. }\end{array}$ & $\begin{array}{l}\text { Missed (or performed } \\
\text { incorrectly or with } \\
\text { difficulty) one or more } \\
\text { steps on one of the } \\
\text { triage task. }\end{array}$ & $\begin{array}{l}\text { Completed all steps } \\
\text { correctly (and without } \\
\text { difficulty) for all triage } \\
\text { tasks. }\end{array}$ \\
\hline Triage Category & $\begin{array}{l}\text { Did not assign a triage } \\
\text { category to the casualty. }\end{array}$ & $\begin{array}{l}\text { Assigned casualty to a } \\
\text { triage category lower or } \\
\text { higher than his or her } \\
\text { true level of urgency } \\
\text { (i.e., undertriaged, } \\
\text { overtriaged). }\end{array}$ & $\begin{array}{l}\text { Assigned casualty to the } \\
\text { correct triage category. }\end{array}$ \\
\hline Time & $\begin{array}{l}\text { Took more than } 1 \\
\text { minute to complete the } \\
\text { triage assessment of the } \\
\text { casualty. }\end{array}$ & $\begin{array}{l}\text { Took less than } 1 \text { minute } \\
\text { (but more than } 30 \\
\text { seconds) to complete } \\
\text { the triage assessment of } \\
\text { the casualty. }\end{array}$ & $\begin{array}{l}\text { Took } 30 \text { seconds or less to } \\
\text { complete the triage } \\
\text { assessment of the casualty. }\end{array}$ \\
\hline
\end{tabular}




\section{Appendix F: Interview Protocol}

\section{Questions for Sample 1}

1. You mentioned that you would be certifying your team this week, have you had an opportunity to develop any tools to do this?

2. There are several established methods of conducting triage, such as START, SALT, CERT, and others. Is there a standard that the ARMY prefers? What tagging system did you use in Atterbury? Were you provided with Red, Yellow, Green and Black tags?

3. Medical triage typically asserts that you should not treat the victim for his injuries but instead sort, assess, then transport. The only treatment should involve, repositioning the airway, stopping the bleeding and elevating extremities for treating shock. Is this what you were told at Atterbury as well? The presence of burns and fractures help you to categorize the victim, but don't necessitate treatment during triage.

4. Do you require a buddy system or a team of individuals to carry out triage tasks? If they are currently being trained as individual tasks, would you be in favor of making them collective? Are you interested in rating them on communication and coordination while carrying out the triage tasks?

5. Would you like the assessment to be designed for field use, classroom, or both?

6. We have paper-based triage assessments and versions that allow you to customize the items using Excel. Do you have preferences based on ease of use or flexibility? We would like to give you a demonstration of what we have developed which might make it easier for you to answer this item.

7. If you are still attending training at the CTC, will we be able to pilot the assessments then with you and your unit?

8. Did you have questions/concerns on any of the assessments we've provided so far? For instance, is the GO/NO GO or Performed Correctly/Incorrectly/Task Excluded or some other scoring scheme best for you?

9. Do you have a contact at Camp Atterbury that would be willing to provide us their insight on measuring these kinds of medical triage tasks?

10. A contact at the CTC? The BDE providing the DCRF task list? 


\section{Questions for Sample 2}

1. How do you refer to the injured civilian during training exercises? Casualty, victim, patient, injured civilian, other?

2. Is there current classroom training to explain the basic triage process for mass casualties? Describe it. Do you currently have assessments for your classroom training?

3. When conducting mass casualty exercises involving triage, describe the different roles played by each member of the platoon (e.g., individuals conducting triage, litter carriers, Medics, Combat Life Saver personnel, etc.). How do these different roles interact and work together? What type of coordination and communication is involved? How do you know when these roles are working together effectively or ineffectively?

4. Do you measure the time it takes to conduct triage on each civilian? If yes, is there a standard that you go by?

5. What factors do you use in determining whether a $\underline{\text { Soldier }}$ is ready to conduct triage during an actual mass casualty event?

6. What factors do you use in determining whether the unit is ready to conduct triage during an actual mass casualty event?

7. What are your criteria for successfully performing triage?

8. Does assessing performance at the individual level on triage predict how well the unit (e.g., platoon) will do on triage?

9. We would recommend that the Soldiers first study basic triage procedures prior to participating in an exercise and being rated with this scale. There are a number of well-established triage protocols from FEMA and other governmental and non-government agencies. Are Soldiers trained using such guides, if so which ones, and if not, why not?

10. Triage maneuvers such as the Head-Tilt method, should be reviewed prior to exercises. Is it practical to expect that Soldiers would be trained on triage protocols prior to participating in a mass casualty exercise involving triage? Why or why not?

11. When conducting triage, do you typically expect Soldiers to perform tasks individually or in teams of two or three? Explain. If it is in teams, how should they interact? What does right look like? What type of coordination and communication is required (if any)?

12. Do you typically have multiple assessors per exercise? How many do you have and which aspects of the exercise are they rating? 
13. Is the scale used in the assessment on the following pages practical for your rating purposes? Should it be more of a go/no go scale? What changes, if any, would you suggest? Are there any features that might prove burdensome?

14. Do you foresee any challenges with the assessment? What would you change about the tool?

15. How does the assessment help with preparing Soldiers for triage operations over the tools currently being used?

\section{Questions for Sample 3}

1. Do you typically have multiple assessors per exercise? How many do you have and which aspects of the exercise are they rating?

2. Is the scale used in the assessment on the following pages practical for your rating purposes? Should it be more of a go/no go scale? What changes, if any, would you suggest? Are there any features that might prove burdensome?

3. Do you foresee any challenges with the assessment? What would you change about the tool?

4. How does the assessment help with preparing Soldiers for triage operations over the tools currently being used? 